\begin{tabular}{|l|l|l|}
\hline Received : Juli 2019 & Accepted : September 2019 & Published : Oktober 2019 \\
\hline
\end{tabular}

\title{
Perancangan Pengontrolan Overhead Crane Menggunakan Kabel dan Nirkabel Berbasis Arduino
}

\author{
Ari Novriadi ${ }^{1^{*}}$ \\ ${ }^{1 *}$ Universitas Putera Batam \\ *arnodi92@gmail.com
}

\begin{abstract}
In general, Overhead Crane control is operated by using a Push Button which is hung with a cable on the upper frame of the Overhead Crane. In this case, humans must also be able to keep a distance when controlling Overhead Crane who is working to transport materials to avoid accidental use of Overhead Crane. With the Overhead Crane controlling device using wireless, it makes it easier for operators to not always follow the direction the Overhead Crane moves as well to reduce unwanted accidents when using Overhead Crane. The design of this tool consists of software design and hardware design. The design of overhead crane control uses a cable consisting of several series of Push Buttons arranged in a plastic box and then hung on the Girder Crane side. The Push Button input leg is given a voltage of 12VDC, while the Push Button output leg is connected with 12VDC Relay points contacts to execute the electric mechanical Overhead Crane. The design of Overhead Crane control using wireless consists of several components, including: Arduino Mega 2560 combined with USB Host Shield. Bluetooth CSR 4.0 Dongle is connected with USB Host Shield port for data communication media between Arduino Mega 2560 with Bluetooth Joystick PlayStation 3 (PS3). This Overhead Crane control test is done by activating the Power Supply then try controlling the Overhead Crane then deactivating the Power Supply. This test was carried out 3 times. The results obtained from this test are 100\% successful without any errors/damage.
\end{abstract}

Keywords: Overhead Crane, Push button, Joystick PlayStation 3

\begin{abstract}
Abstrak
Pada umumnya, pengontrolan Overhead Crane di operasikan dengan menggunakan Push Button yang digantung bersama kabel pada kerangka bagian atas Overhead Crane. Dalam hal ini, manusia juga harus bisa menjaga jarak saat mengontrol Overhead Crane yang sedang bekerja mengangkut bahan material agar terhindarnya dari kecelakaan penggunaan Overhead Crane. Alat pengontrolan Overhead Crane menggunakan kabel ini untuk alat kontrol cadangan yang digunakan disaat sistem kontrol menggunakan nirkabel kondisi rusak atau tahap pembaruan program hardware. Perancangan alat ini terdiri dari perancangan perangkat lunak dan perancangan perangkat keras. Perancangan pengontrolan Ovehread Crane menggunakan kabel terdiri dari beberapa rangkaian Push Button yang disusun pada kotak plastik lalu di gantung pada sisi Girder Crane. Untuk kaki input Push Button diberi tegangan 12VDC, sedangkan kaki output Push Button dihubungkan dengan kontak-kontak poin Relay 12VDC untuk mengeksekusi mekanik elektrik Overhead Crane. Perancangan pengontrolan Overhead Crane menggunakan nirkabel terdiri dari beberapa komponen, antara lain: Arduino Mega 2560 yang dikombinasikan dengan USB Host Shield. Bluetooth CSR 4.0 Dongle dihubungkan dengan port USB Host Shield untuk media komunikasi data antara Arduino Mega 2560 dengan Bluetooth Joystick PlayStation 3 (PS3). Pengujian pengontrolan Overhead Crane ini dilakukan dengan mengaktifkan Power Supply lalu mencoba pengontrolan Overhead Crane kemudian menonaktifkan kembali Power Supply. Pengujian ini dilakukan sebanyak 3 kali. Hasil yang diperoleh dari pengujian ini yaitu berhasil $100 \%$ tanpa ada error/rusak.
\end{abstract}

Kata kunci: Overhead Crane, Push Button, Joystick PlayStation 3 


\section{Pendahuluan}

Overhead crane sebuah alat berat yang sangat banyak ditemukan di berbagai dunia industri, pabrik, maupun bengkel yang digunakan untuk mengangkut bahan material. manusia harus bisa menjaga jarak saat mengontrol overhead crane yang sedang bekerja mengangkut bahan material Agar terhindarnya dari kecelakaan penggunaan overhead crane karena alat kontrol overhead crane pada umumnya masih banyak di kontrol menggunakan push button yang dihubungkan ke sistem menggunakan kabel.

Agar mempermudah dan memberikan kenyamanan dalam penggunaan overhead crane. tentu membutuhkan sebuah alat pengontrol overhead crane jarak jauh untuk mempermudah manusia agar tidak selalu mengikuti kemana arah overhead crane bergerak dan terhindarnya dari kecelakaan yang tidak diinginkan. Alat kontrol jarak jauh yang digunakan adalah Joystick PlayStation3 menggunakan media komunikasi Bluetooth dan diproses oleh arduino yang dikombinasikan dengan USB Host Shield.

\section{Tinjauan Pustaka}

\section{Board Arduino Mega 2560}

Board Arduino Mega 2560 adalah sebuah board Arduino yang menggunakan IC Mikrokontroler ATmega 2560. Board ini memiliki 54 digitalinput / output (15 buah di antaranya dapat digunakan sebagai output PWM), 16 buah analoginput, 4 UARTs (UniversalAsynchronous receiver / transmitter), osilator kristal $16 \mathrm{MHz}$, koneksi USB, jack power,soket ICSP (In-Circuit System Programming) dan tombol reset[1].

\section{Arduino USB Host Shield}

Arduino USB Host Shield adalah papan sederhana yang digunakan untuk menghubungkan perangkat USB. USB Host Shield berfungsi sebagai media komunikasi data perangkat USB dengan papan Arduino Uno. USB Host Shield adalah pengontrolperipheral USB yang berisi logika digital dan sirkuit analog yang diperlukan untuk mengimplementasikan piferal USB kecepatan penuh. Papan board ini mendukung perangkat USB seperti keyboard, mouse, joystick dan lain-lain. Papan Board ini menggunakan tegangan $5 \mathrm{~V}$ dan arus $500 \mathrm{~mA}[2]$.

\section{Joystick PlayStation 3 (PS3)}

Kontroler nirkabel DUALSHOCK 3 untuk sistem PlayStation 3 memberikan pengalaman bermain paling intuitif dengan sensor tekanan disetiap tombol aksi dan dimasukkannya teknologi penginderaan gerak SIXAXISTM yang sangat sensitive. DUALSHOCK 3 memanfaatkan teknologi Bluetooth nirkabel dan kabel USB pengontrol untuk mengisi daya pengontrol secara mulus dan otomatis[3].

\section{Motor DC}

Motor DC adalah motor yang bergerak berputar 360 derajat, pada umumnya disebut dinamo dan biasanya digunakan sebagai penggerak roda. Apabila kutub positif dan negatif sumber yang dipasang ditukar, maka motor DC akan berputar berlawanan arah dari arah putaran sebelumnya[1].

\section{Worm Gear}

Worm gear disebut juga denga roda gigi cacing adalah sejenis roda gigi dengan bentuk konstruksinya sama dengan spur gear dengan perbedaan pada bagian lebar roda terdapat kelengkungan (radius) yang besarnya sama dengan radius ulir cacing. Penggunaan pada roda gigi biasanya untuk mereduksi kecepatan, roda gigi dalam operasionalnya akan "mengunci sendiri" sehingga tidak dapat diputar pada arah yang berlawanan. Keuntungan dari roda gigi adalah dengan memberikan input minimal dapat dihasilkan output dengan kekuatan maksimal[4].

\section{Push Button}

Push yang berarti tekan dan Button yang artinya tombol adalah salah satu komponen yang dikendalikan secara manual oleh manusia. Push Button biasanya digunakan dalam panel listrik yang berfungsi utuk menghubungkan dan memutuskan aliran listrik ke beban. Push Button terbagi menjadi 3 jenis, 
antara lain: Push Button NC (Normally Open), Push Button NO (Normally Close), dan Push Button NO/NC[5].

Push Buttonswitch (saklar tombol tekan) adalah perangkat / saklar sederhana yang berfungsi untuk menghubungkan atau memutuskan aliran arus listrik dengan sistem kerja tekan unlock (tidak mengunci)[6].

\section{Bluetooth CSR 4.0 Dongle}

Bluetooth adalah sebuah teknologi komunikasi wireless dengan jangkauan yang terbatas yaitu rentang hingga 100 meter. Sebagian orang, Bluetooth mungkin hanya sebagai media komunikasi atau alat transfer data yang terdapat pada telepon seluler (handphone) dan laptop, atau sebuah perangkat USB portable yang bekerja secara plug dan play pada perangkat komputer yang sering disebut dengan Bluetooth Dongle [7].

\section{Relay}

Relay adalah saklar (Switch) yang dioperasikan secara listrik dan merupakan komponen Elekromechanical (elektromekanikal) yang terdiri dari 2 bagian utama yakni electromagnet (Coil) dan mekanikal (seperangkat kontak saklar/switch). Relay menggunakan prinsip Elektromegnetik untuk menggerakkan kontak saklar sehingga dengan arus listrik yang kecil (low power) dapat menghantarkan listrik yang bertegangan lebih tinggi[8].

\section{Buzzer}

Buzzer adalah perangkat elektronik yang mengeluarkan suara monotone. Suara ini dihasilkan oleh getaran mekanis yang diakibatkan oleh arus listrik. Arus listrik yang diterima digunakan untuk proses osilasi yang mengakibatkan getaran antara dua bidang. Getaran ini menimbulkan suara yang dikeluarkan mmelalui tabung resonansi sehingga terdengar seperti sebuah nada. Karena monotone, maka hanya ada satu nada 'beep' yang dikeluarkan oleh BuzzerBuzzer memiliki dua kaki, di mana salah satu kakinya lebih panjang dari yang lainnya [9].

\section{Limit Switch}

Limit Switch adalah alat yang berfungsi untuk memutuskan dan menghubungkan arus listrik pada suatu rangkaian, berdasarkan struktur mekanik, Limit switch memiliki tiga buah terminal, yaitu central terminal, normally close (NC) terminal, dan normally open (NO) terminalTerminal $\mathrm{NC}$, NO, dan central dapat digunakan untuk memutuskan aliran listrik pada suatu rangkaian atau sebaliknya.Limit switch merupakan jenis saklar yang dilengkapi dengan katup yang berfungsi menggantikan tombol[8].

\section{Power Supply}

Power Supply atau dalam bahasa Indonesia disebut dengan catu daya adalah suatu alat listrik yang dapat menyediakan energy listrik untuk perangkat listrik ataupun elektronika lainnya. Pada dasarnya power supply atau catu daya ini memerlukan sumber energy listrik yang kemudian mengubahnya menjadi energy listrik yang dibutuhkan oleh perangkat elektronika lainnya Oleh karena itu power supply kadang-kadang disebut juga dengan istilah Electric Power Converter[10].

\section{Metoda Penelitian \\ Perancangan Komponen Elektrik}

Pengontrolan Overhead Crane ini menggunakan beberapa komponen elektronik untuk menggerakan motor Overhead Crane. Komponen elektronik yang perlu dirangkai antara lain: Arduino Mega 2560 yang dikombinasikan dengan USB Host Shield yang dihubungkan dengan Bluetooth CSR 4.0 Dongle sebagai media komunikasi Arduino Mega 2560 dengan Joystick PlayStation 3 (PS3), Push Button, Relay yang menggunakan input coil 12 VDC dan 5 VDC, Lampu, Buzzer, motor DC, dan power supply berfungsi sebagai catu daya untuk seluruh komponen elektronik.

Perancangan elektrik terbagi 2 bagian yaitu: perancangan elektrik menggunakan sistem arduino dan perancangan elektrik yang tidak menggunakan sistem arduino. Sistem perancangan elektrik menggunakan sistem arduino bisa digambar dalam bentuk single 
line berbentuk gambar hardware. Sedangkan sistem perancangan elektrik yang tidak menggunakan sistem arduino pada umumnya hanya digambar dalam bentuk single line diagram dan wiring diagram listrik.

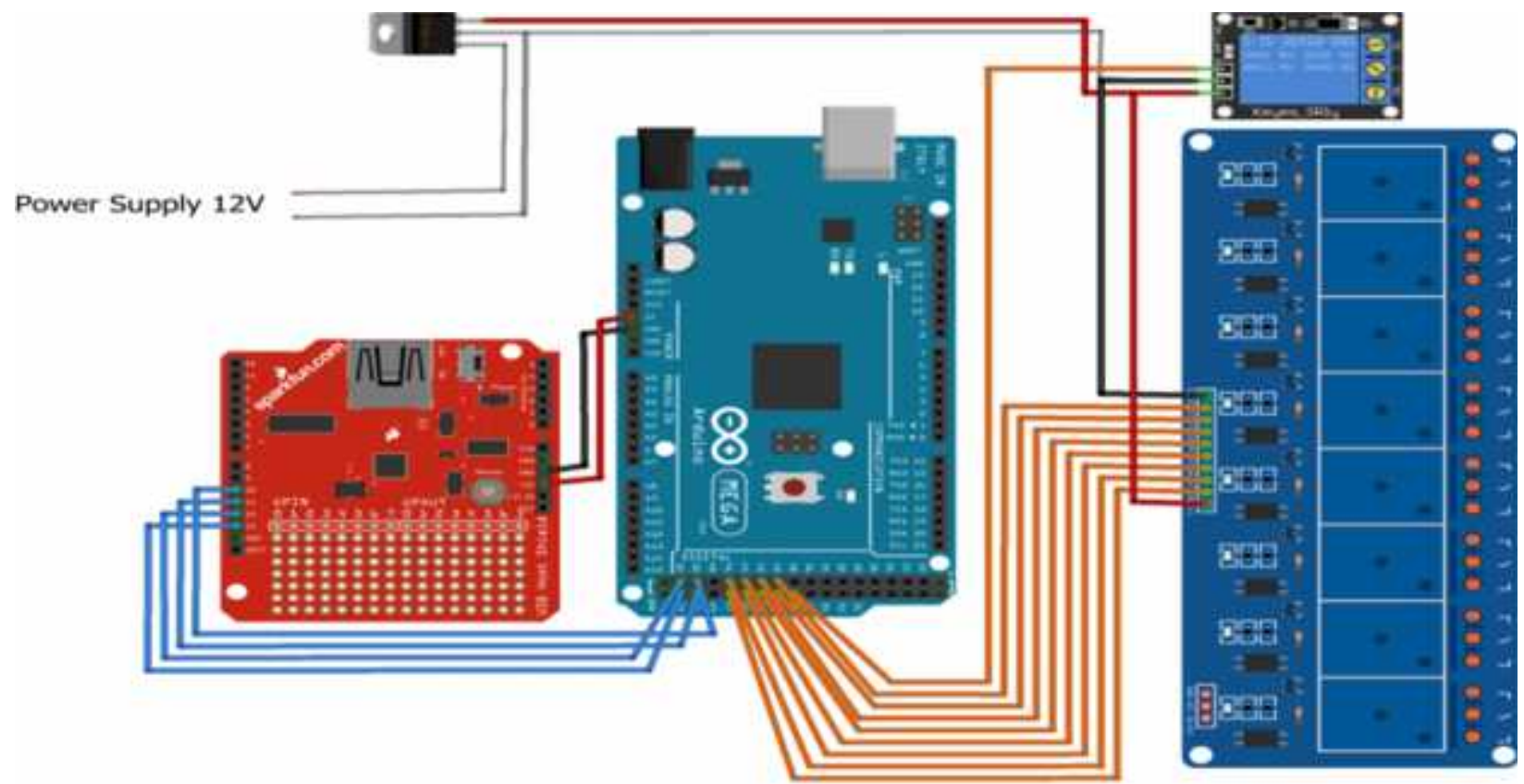

Gambar 1. Desain Sistem Harware Pengontrolan Nirkabbel

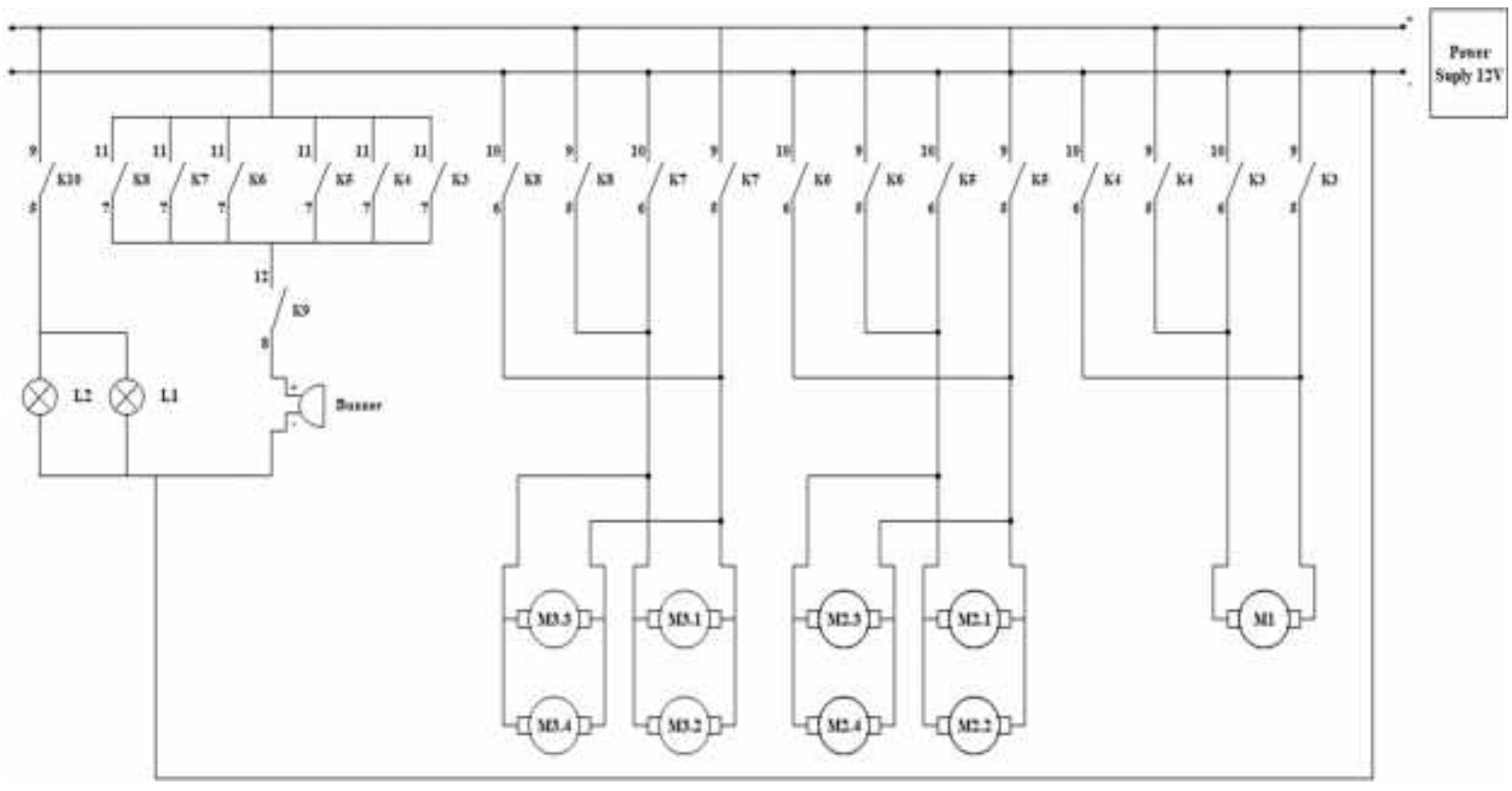

Gambar 2. Single Line Diagram Mekanik Elektrik

\section{Perancangan Perangkat Lunak}

Perancangan perangkat

lunak

menunjukkan bagaimana sistem kerja alat yang dibuat. Alur program pada penelitian ini adalah Arduino menerima sinyal dari Joystick Playstation3 untuk mengakses modul-modul relay yang akan mengontrol relay 12 VDC untuk mengakses mekanik overhead crane. 
berikut algoritma Arduino untuk mengakses overhead crane antara lain:

a. Algoritma

if(PS.3getButtonClick(SELECT)) untuk memutuskan seluruh power supply mekanik overhead crane.

b. Algoritma (PS3.getButtonClick(SELECT)) untuk menghubungkan kembali Power Supply mekanik overhead crane.

c. Algoritma if (PS3.getButtonPress(TRIANGLE)) \& if (PS3.getButtonPress(R2)) untuk menaikan pengait hoist crane.

d. Algoritma if (PS3.getButtonPress(CROSS)) $\&$ if (PS3.getButtonPress(L2)) untuk menurunkan pengait hoist crane.

e. Algoritma

(PS3.getButtonPress(RIGHT)), if (PS3.getAnalogHat (LeftHatX>180)) \& if (PS3.getAnalogHat(RightHatX>180)) untuk mengerakan girder crane ke kanan.

f. Algoritma if (PS3.getButtonPress (LEFT)), if(PS3.getAnalogHat $($ LeftHatX $<90)) \quad \&$
if(PS3.getAnalogHat(RightHatX<90)) untuk menggerakan girder crane ke kiri.

g. Algoritma if (PS3.getButtonPress(UP)), if(PS3.getAnalogHat $($ LeftHatY $<90)) \quad \&$ if(PS3.getAnalogHat $($ RightHatY<90)) untuk menggerakan runway crane maju

h. Algoritma if (PS3.getButtonPress(DOWN)), if (PS3.getAnalogHat(LeftHatY>180)) \& if (PS3.getAnalogHat(RightHatY>180)) untuk menggerakan runway crane mundur

i. Algoritma if (PS3.getButtonPress $(\mathrm{ON})$ ) untuk mengaktifkan lampu 12 VDC.

j. Algoritma if (PS3.getButtonPress(OFF)) untuk mematikan lampu 12 VDC.

\section{Diagram Blok Pengontrolan Overhead Crane}

Diagram blok merupakan suatu bagian penting dalam pembuatan alat ini. Diagram blok digunakan untuk memudahkan proses perancangan dari masing masing rangkaian listrik sehingga membentuk gabungan satu sistem.

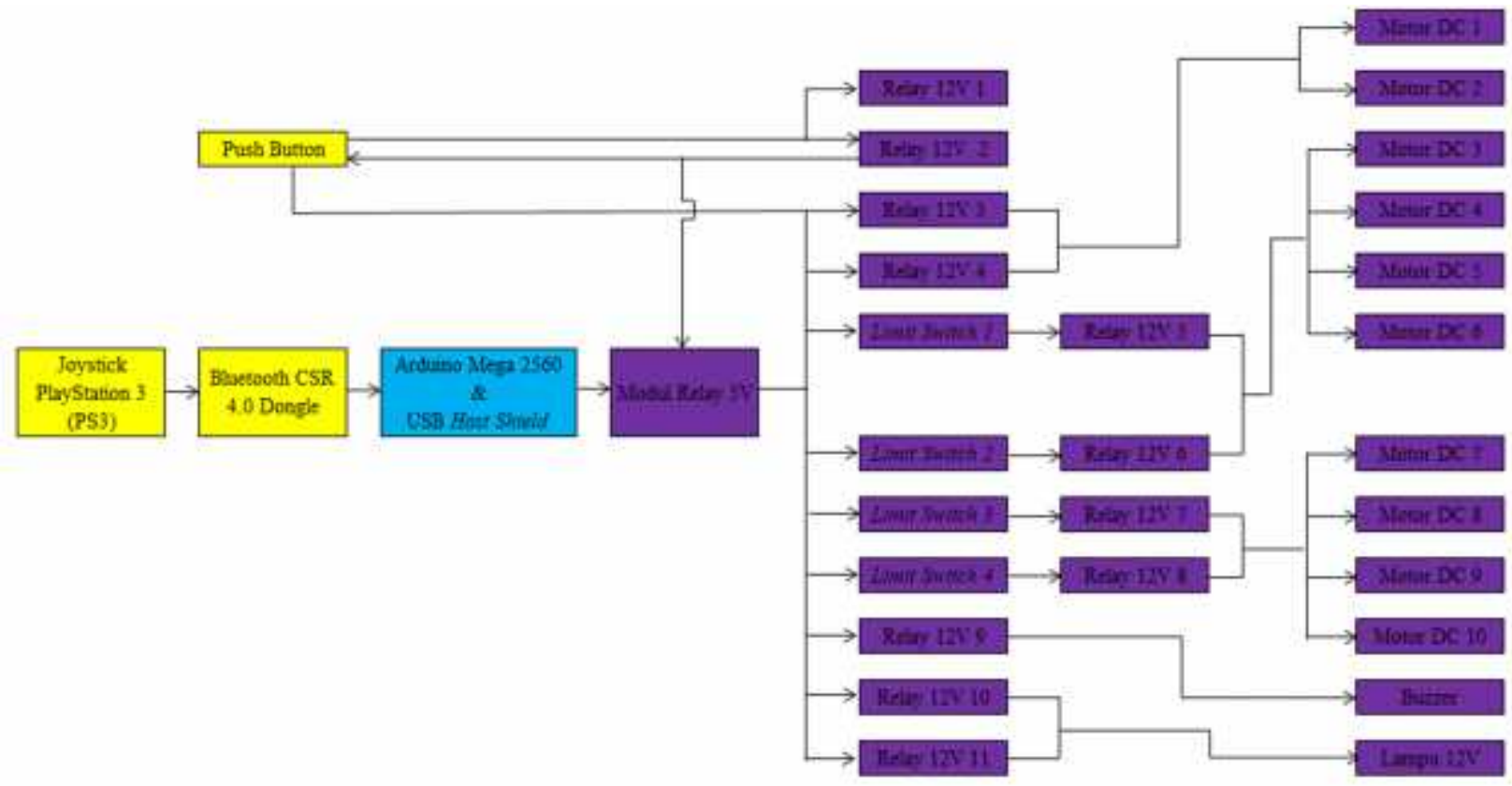

Gambar 3. Diagram Blok Pengontrolan Overhead Crane 


\section{Hasil Dan Pembahasan}

\section{Hasil Pengujian Alat Kontrol Menggunakan Kabel}

Pengujian alat pengontrol menggunakan kabel dengan cara menekan salah satu tombol push button yang ada secara bergantian. Hasil pengujian alat kontrol menggunakan kabel dapat di lihat dari relay 12 VDC yang bekerja ketika tombol push button ditekan. Berikut hasil pengujian alat pengontrolan overhead crane menggunakan kabel.

Tabel 1. Hasil Pengujian Pengontrolan Menggunakan Kabel

\begin{tabular}{|c|c|c|c|}
\hline $\begin{array}{l}\text { Nama } \\
\text { Bagian }\end{array}$ & Fungsi tombol & $\begin{array}{c}\text { Alamat } \\
\text { Relay } 12 \\
\text { VDC }\end{array}$ & Ket \\
\hline $\begin{array}{c}\text { Push } \\
\text { Button } 1\end{array}$ & $\begin{array}{l}\text { Tombol instruksi } \\
\text { Power Supply } \\
\text { kontrol }\end{array}$ & $\mathrm{K} 1$ & $\mathrm{Ok}$ \\
\hline $\begin{array}{c}\text { Push } \\
\text { Button } 2\end{array}$ & $\begin{array}{l}\text { Tombol instruksi } \\
\text { maju }\end{array}$ & $\mathrm{K} 7$ & $\mathrm{Ok}$ \\
\hline $\begin{array}{c}\text { Push } \\
\text { Button } 3\end{array}$ & $\begin{array}{l}\text { Tombol } \\
\text { instruksimundur }\end{array}$ & $\mathrm{K} 8$ & $\mathrm{Ok}$ \\
\hline $\begin{array}{c}\text { Push } \\
\text { Button } 4\end{array}$ & $\begin{array}{l}\text { Tombol instruksi } \\
\text { ke kanan }\end{array}$ & K5 & $\mathrm{Ok}$ \\
\hline $\begin{array}{c}\text { Push } \\
\text { Button } 5\end{array}$ & $\begin{array}{l}\text { Tombol instruksi } \\
\text { lampu ON }\end{array}$ & K10 & Ok \\
\hline $\begin{array}{c}\text { Push } \\
\text { Button } 6\end{array}$ & $\begin{array}{l}\text { Tombol instruksi } \\
\text { Buzzer }\end{array}$ & K9 & $\mathrm{Ok}$ \\
\hline $\begin{array}{c}\text { Push } \\
\text { Button } 7\end{array}$ & $\begin{array}{l}\text { Tombol instruksi } \\
\text { lampu OFF }\end{array}$ & K11 & $\mathrm{Ok}$ \\
\hline $\begin{array}{c}\text { Push } \\
\text { Button } 8\end{array}$ & $\begin{array}{l}\text { Tombol instruksi } \\
\text { ke kiri }\end{array}$ & K6 & Ok \\
\hline $\begin{array}{c}\text { Push } \\
\text { Button } 9\end{array}$ & $\begin{array}{l}\text { Tombol instruksi } \\
\text { turun }\end{array}$ & $\mathrm{K} 4$ & Ok \\
\hline $\begin{array}{c}\text { Push } \\
\text { Button } 10\end{array}$ & $\begin{array}{l}\text { Tombol instruksi } \\
\text { naik }\end{array}$ & K3 & Ok \\
\hline $\begin{array}{c}\text { Push } \\
\text { Button } 11\end{array}$ & $\begin{array}{l}\text { Tombol instruksi } \\
\text { pengalihan } \\
\text { kontrol }\end{array}$ & $\mathrm{K} 2$ & $\mathrm{Ok}$ \\
\hline
\end{tabular}

\section{Hasil Pengujian Pengontrolan Menggunakan Nirkabel}

Pengujian tombol-tombol Joystick PlayStation 3 (PS3) diuji secara bertahap dengan cara menekan salah satu tombol button atau mengontrol salah satu arah analog Joystick PlayStation 3 (PS3) yang ada secara bergantian. Hasil pengujian dapat dilihat melalui serial monitorSoftware Arduino IDE dan dapat di cek dari lampu indicator modul Relay yang aktif sesuai dengan intruksi Arduino Mega 2560.
Tabel 2. Hasil Pengujian Pengontrolan Menggunakan Nirkabel

\begin{tabular}{|c|c|c|c|}
\hline $\begin{array}{c}\text { Bagian Tombol } \\
\text { Joystick } \\
\text { PlayStation3 }\end{array}$ & $\begin{array}{l}\text { Serial } \\
\text { Monitor } \\
\text { Arduino } \\
\text { IDE }\end{array}$ & $\begin{array}{l}\text { Pin } \\
\text { signal } \\
\text { Modul } \\
\text { Relay }\end{array}$ & Ket \\
\hline$\Delta$ Button & $\begin{array}{c}\text { Pad } \\
\text { Segitiga }\end{array}$ & IN1 & Sukses \\
\hline$\square$ Button & $\begin{array}{c}\text { Pad } \\
\text { Kotak }\end{array}$ & IN8 & Sukses \\
\hline X Button & Pad X & IN2 & Sukses \\
\hline O Button & $\begin{array}{c}\text { Pad } \\
\text { Bulat }\end{array}$ & IN7 & Sukses \\
\hline $\begin{array}{l}\text { Up Directional } \\
\text { Button }\end{array}$ & Pad Atas & IN5 & Sukses \\
\hline $\begin{array}{c}\text { Down Directional } \\
\text { Button }\end{array}$ & $\begin{array}{c}\text { Pad } \\
\text { Bawah }\end{array}$ & IN6 & Sukses \\
\hline $\begin{array}{c}\text { Right Directional } \\
\text { Button }\end{array}$ & $\begin{array}{c}\text { Pad } \\
\text { Kanan }\end{array}$ & IN3 & Sukses \\
\hline $\begin{array}{l}\text { Left Directional } \\
\text { Button }\end{array}$ & Pad Kiri & IN 4 & Sukses \\
\hline R1 Button & $\mathrm{R} 1$ & IN7 & Sukses \\
\hline R2 Button & $\mathrm{R} 2$ & IN1 & Sukses \\
\hline L1 Button & L1 & IN8 & Sukses \\
\hline L2 Button & L2 & IN2 & Sukses \\
\hline Start Button & Start & $\mathrm{S}$ & Sukses \\
\hline Select Button & Select & $\mathrm{S}$ & Sukses \\
\hline $\begin{array}{c}\text { Right Analog Axis } \\
\text { Y+ }\end{array}$ & $\begin{array}{l}\text { Analog } \\
\text { Kanan } \\
\text { Bawah }\end{array}$ & IN6 & Sukses \\
\hline $\begin{array}{c}\text { Right Analog Axis } \\
\text { Y- }\end{array}$ & $\begin{array}{l}\text { Analog } \\
\text { Kanan } \\
\text { Atas }\end{array}$ & IN5 & Sukses \\
\hline $\begin{array}{c}\text { Right Analog Axis } \\
\mathrm{X}+\end{array}$ & $\begin{array}{l}\text { Analog } \\
\text { Kanan } \\
\text { Kanan }\end{array}$ & IN3 & Sukses \\
\hline $\begin{array}{c}\text { Right Analog Axis } \\
\text { X- }\end{array}$ & $\begin{array}{c}\text { Analog } \\
\text { Kanan } \\
\text { Kiri }\end{array}$ & IN 4 & Sukses \\
\hline $\begin{array}{c}\text { Left Analog Axis } \\
\text { Y+ }\end{array}$ & $\begin{array}{l}\text { Analog } \\
\text { Kiri } \\
\text { Bawah } \\
\end{array}$ & IN6 & Sukses \\
\hline $\begin{array}{l}\text { Left Analog Axis } \\
\text { Y- }\end{array}$ & $\begin{array}{c}\text { Analog } \\
\text { Kiri Atas }\end{array}$ & IN5 & Sukses \\
\hline $\begin{array}{l}\text { Left Analog Axis } \\
\mathrm{X}^{+}\end{array}$ & $\begin{array}{c}\text { Analog } \\
\text { Kiri } \\
\text { Kanan } \\
\end{array}$ & IN3 & Sukses \\
\hline $\begin{array}{l}\text { Left Analog Axis } \\
\text { X- }\end{array}$ & $\begin{array}{l}\text { Analog } \\
\text { Kiri Kiri }\end{array}$ & IN 4 & Sukses \\
\hline
\end{tabular}

\section{Hasil Pengujian Motor 12VDC}

Pengujian motor 12VDC terdiri dari 3 bagian antara lain: pengujian Motor 12VDC sisi Hoist Crane, pengujian Motor 12VDC sisi Girder Crane, Pengujian Motor 12VDC sisi Runway Crane. pengujian Motor 12VDC dilakukan untuk mengetahui Kemampuan atau 
kekuatan Motor listrik DC saat sedang menggangkut material.

Motor listrik DC langsung dihubungkang dengan tegangan 12VDC. Pengujian Overhead Crane ini dapat dilakukan dengan mengukur tegangan dan arus listrik saat Overhead Crane tidak memikul beban atau pun sedang memikul beban. Berikut hasil dari pengujian Overhead Crane.

Tabel 3. Hasil Pengujian Kapasitas Motor DC

\begin{tabular}{|c|c|c|c|c|}
\hline $\begin{array}{l}\text { Nama } \\
\text { Bagian }\end{array}$ & Status & Beban & V & A \\
\hline \multirow{12}{*}{$\begin{array}{c}\text { Motor } 12 \\
\text { VDC sisi } \\
\text { hoist crane }\end{array}$} & Naik & \multirow{2}{*}{$0 \mathrm{~kg}$} & $12 \mathrm{VDC}$ & $80 \mathrm{~mA}$ \\
\hline & Turun & & $12 \mathrm{VDC}$ & $60 \mathrm{~mA}$ \\
\hline & Naik & \multirow{2}{*}{$1 \mathrm{~kg}$} & $12 \mathrm{VDC}$ & $160 \mathrm{~mA}$ \\
\hline & Turun & & $12 \mathrm{VDC}$ & $70 \mathrm{~mA}$ \\
\hline & Naik & \multirow{2}{*}{$2 \mathrm{~kg}$} & $12 \mathrm{VDC}$ & $240 \mathrm{~mA}$ \\
\hline & Turun & & $12 \mathrm{VDC}$ & $80 \mathrm{~mA}$ \\
\hline & Naik & \multirow{2}{*}{$3 \mathrm{~kg}$} & $12 \mathrm{VDC}$ & $320 \mathrm{~mA}$ \\
\hline & Turun & & $12 \mathrm{VDC}$ & $90 \mathrm{~mA}$ \\
\hline & Naik & \multirow[b]{2}{*}{$4 \mathrm{~kg}$} & $12 \mathrm{VDC}$ & $400 \mathrm{~mA}$ \\
\hline & Turun & & $12 \mathrm{VDC}$ & $100 \mathrm{~mA}$ \\
\hline & Naik & \multirow{2}{*}{$5 \mathrm{~kg}$} & $12 \mathrm{VDC}$ & $480 \mathrm{~mA}$ \\
\hline & Turun & & $12 \mathrm{VDC}$ & $110 \mathrm{~mA}$ \\
\hline \multirow{12}{*}{$\begin{array}{c}\text { Motor } 12 \\
\text { VDC sisi } \\
\text { girder } \\
\text { crane }\end{array}$} & Kanan & \multirow{2}{*}{$0 \mathrm{~kg}$} & $12 \mathrm{VDC}$ & $400 \mathrm{~mA}$ \\
\hline & Kiri & & $12 \mathrm{VDC}$ & $400 \mathrm{~mA}$ \\
\hline & Kanan & $1 \mathrm{ko}$ & $12 \mathrm{VDC}$ & $500 \mathrm{~mA}$ \\
\hline & Kiri & $1 \mathrm{~kg}$ & $12 \mathrm{VDC}$ & $500 \mathrm{~mA}$ \\
\hline & Kanan & $2 \mathrm{ko}$ & $12 \mathrm{VDC}$ & $600 \mathrm{~mA}$ \\
\hline & Kiri & $2 \mathrm{~kg}$ & $12 \mathrm{VDC}$ & $600 \mathrm{~mA}$ \\
\hline & Kanan & $3 \mathrm{l} r$ & $12 \mathrm{VDC}$ & $700 \mathrm{~mA}$ \\
\hline & Kiri & $3 \mathrm{Kg}$ & $12 \mathrm{VDC}$ & $700 \mathrm{~mA}$ \\
\hline & Kanan & 4 lo & $12 \mathrm{VDC}$ & $800 \mathrm{~mA}$ \\
\hline & Kiri & $4 \mathrm{hg}$ & $12 \mathrm{VDC}$ & $800 \mathrm{~mA}$ \\
\hline & Kanan & & $12 \mathrm{VDC}$ & $900 \mathrm{~mA}$ \\
\hline & Kiri & $5 \mathrm{~kg}$ & $12 \mathrm{VDC}$ & $900 \mathrm{~mA}$ \\
\hline \multirow{12}{*}{$\begin{array}{l}\text { Motor } 12 \\
\text { VDC sisi } \\
\text { runway } \\
\text { crane }\end{array}$} & Maju & \multirow{2}{*}{$0 \mathrm{~kg}$} & $12 \mathrm{VDC}$ & $410 \mathrm{~mA}$ \\
\hline & Mundur & & $12 \mathrm{VDC}$ & $410 \mathrm{~mA}$ \\
\hline & Maju & \multirow{2}{*}{$1 \mathrm{~kg}$} & $12 \mathrm{VDC}$ & $520 \mathrm{~mA}$ \\
\hline & Mundur & & $12 \mathrm{VDC}$ & $520 \mathrm{~mA}$ \\
\hline & Maju & \multirow{2}{*}{$2 \mathrm{~kg}$} & $12 \mathrm{VDC}$ & $630 \mathrm{~mA}$ \\
\hline & Mundur & & $12 \mathrm{VDC}$ & $630 \mathrm{~mA}$ \\
\hline & Maju & \multirow{2}{*}{$3 \mathrm{~kg}$} & $12 \mathrm{VDC}$ & $740 \mathrm{~mA}$ \\
\hline & Mundur & & $12 \mathrm{VDC}$ & $740 \mathrm{~mA}$ \\
\hline & Maju & \multirow{2}{*}{$4 \mathrm{~kg}$} & $12 \mathrm{VDC}$ & $850 \mathrm{~mA}$ \\
\hline & Mundur & & $12 \mathrm{VDC}$ & $850 \mathrm{~mA}$ \\
\hline & Maju & \multirow{2}{*}{$5 \mathrm{~kg}$} & $12 \mathrm{VDC}$ & $960 \mathrm{~mA}$ \\
\hline & Mundur & & $12 \mathrm{VDC}$ & $960 \mathrm{~mA}$ \\
\hline
\end{tabular}

\section{Hasil Pengujian Alat}

Hasil pengujian alat pengontrolan Overhead Crane menggunakan kabel dan nirkabel berbasis Arduino diuji sebanyak 3 kali dengan langkah-langkah pengujian yang sama. langkah awal adalah dengan memberikan Power Supply (catu daya) pada komponen-komponen elektrik. Kemudian uji alat pengontrolan mekanik Overhead Crane menggunakan kabel dan nirkabel secara bertahap sesuai dengan fungsi masing masing tombol alat kontrol. Jika pengujian keseluruhan sistem kontrol berjalan susuai dengan perencanaan.

Langkah akhir ialah dengan memutuskan Power Supply (catu daya) yang terhubung dengan komponen-komponen elektrik. Langkah pengujian ini dilakukan sebanyak 3 kali untuk mengetahui apakah sistem pengontrolan Overhead Crane menggunakan kabel dan nirkabel berbasis Arduino sudah berjalan sesuai perencanaan penelitian. Berikut hasil pengujian alat dari yang telah dilakukan sesuai dengan langkah-langkah pengujian.

Tabel 4. Hasil Pengujian Alat

\begin{tabular}{|c|c|c|c|c|}
\hline \multirow[t]{2}{*}{ No } & \multirow{2}{*}{$\begin{array}{c}\text { Bagian } \\
\text { Pengujian } \\
\text { mekanik } \\
\text { elektrik }\end{array}$} & \multicolumn{2}{|c|}{$\begin{array}{c}\text { Sistem } \\
\text { Pengontrolan } \\
\text { Overhead Crane }\end{array}$} & \multirow[t]{2}{*}{ Ket } \\
\hline & & Kabel & nirkabel & \\
\hline \multirow{5}{*}{1} & Hoist Crane & Aktif & Aktif & \multirow{5}{*}{ Berhasil } \\
\hline & $\begin{array}{c}\text { Gantry } \\
\text { Crane }\end{array}$ & Aktif & Aktif & \\
\hline & $\begin{array}{c}\text { Runway } \\
\text { Crane }\end{array}$ & Aktif & Aktif & \\
\hline & Penerang & Aktif & Aktif & \\
\hline & Buzzer & Aktif & Aktif & \\
\hline \multirow{5}{*}{2} & Hoist Crane & Aktif & Aktif & \multirow{5}{*}{ Berhasil } \\
\hline & $\begin{array}{c}\text { Gantry } \\
\text { Crane }\end{array}$ & Aktif & Aktif & \\
\hline & $\begin{array}{c}\text { Runway } \\
\text { Crane }\end{array}$ & Aktif & Aktif & \\
\hline & Penerang & Aktif & Aktif & \\
\hline & Buzzer & Aktif & Aktif & \\
\hline \multirow{5}{*}{3} & Hoist Crane & Aktif & Aktif & \multirow{5}{*}{ Berhasil } \\
\hline & $\begin{array}{c}\text { Gantry } \\
\text { Crane }\end{array}$ & Aktif & Aktif & \\
\hline & $\begin{array}{c}\text { Runway } \\
\text { Crane }\end{array}$ & Aktif & Aktif & \\
\hline & Penerang & Aktif & Aktif & \\
\hline & Buzzer & Aktif & Aktif & \\
\hline
\end{tabular}




\section{Kesimpulan}

Berdasarkan hasil pembahasan dan pengujian alat pengontrol Overhead Crane menggunakan kabel dan nirkabel dapat diambil kesimpulan sebagai berikut:

1. Perancangan pengontrolan Overhead Crane menggunakan kabel terdiri dari beberapa rangkaian Push Button yang disusun pada kotak plastik lalu di gantung pada sisi Girder Crane. untuk kaki input Push Button diberi tegangan 12 VDC, sedangkan kaki output Push Button dihubungkan dengan kontak-kontak poin Relay 12 VDC untuk mengeksekusi mekanik elektrik Overhead Crane.

2. Perancangan pengontrolan Overhead Crane menggunakan nirkabel terdiri dari beberapa komponen, antara lain: Arduino Mega 2560 yang dikombinasikan dengan USB Host Shield. Bluetooth CSR 4.0 Dongle dihubungkan dengan port USB Host Shield untuk media komunikasi data antara Arduino Mega 2560 dengan Bluetooth Joystick PlayStation 3 (PS3). Pin signal modul-modul Relay dihubungkan dengan pin-pin Arduino Mega 2560 sesuai dengan program yang dirancang. Kontak poin NO modul-modul modul Relay dihubungkan dengan kontak-kontak poin Relay 12 VDC untuk mengeksekusi mekanik elektrik Overhead Crane.

3. Alat kontrol menggunakan kabel sebagai alat kontrol cadangan. Alat kontrol menggunakan kabel digunakan disaat sistem alat kontrol menggunakan nirkabel rusak atau dalam tahap perbaikan.

\section{Saran}

Berikut saran dalam pengembangan alat pengontrolan Overhead Crane menggunakan kabel dan nirkabel untuk mencapai yang lebih baik, antara lain:

1. Sistem alat kontrol kabel dan nirkabel ini diharapkan dapat diimplementasikan bukan hanya untuk pengontrolan Overhead Cranesaja, namun dapat diimplementasikan untuk pengontrolan peralatan yang lain.
2. Sistem alat kontrol nirkabel hanya memanfaatkan Bluetooth sebagai komunikasi data ke sistem, diharapkan untuk penelitian selanjutnya dapat memanfaatkan WiFi sebagai komunikasi data nirkabel.

3. Sistem pengontrolan Overhead Crane ini hanya memanfaatkan tombol yang dikontrol melalui sentuhan, diharapkan untuk penelitian selanjutnya dapat dikontrol melalui suara atau gerakan tubuh manusia.

\section{Daftar Pustaka}

[1] H. \& D. A. Andrianto, "Arduino Belajar Cepat dan Pemrograman," Bandung: Informatika Bandung, 2016.

[2] Vismay Deshpande, L. Y. Kankaria, Pritesh, Shubham, and S. M. R5, "Data Transfer between Flash Drives using Bluetooth," Int. J. Adv. Res. Comput. Sci. Manag. Stud., vol. 4, no. 10, pp. 150-155, 2016.

[3] Sony Interactive Entertainment LLC, "DualShock®3 Wireless Control," 2019. [Online]. Available: https://www.playstation.com/enus/explore/accessories/dualshock-3-ps3/.

[4] Y. R. Nugroho, R. Winarso, and Q. Qomaruddin, "Rancang Bangun Mekanisme Ulir Dan Roda Gigi Cacing Pada Meja Mesin Planer Otomatis," J. Crankshaft, vol. 2, no. 1, pp. 35-42, 2019.

[5] M. Yusuf, Isnawaty, and R. Rahmat, "Implementasi Robot Line Follower Penyiraman Tanaman Otomatis Menggunakan Metode ProportionalIntegral-Derivative Controller (PID)," semsnTIK, vol. 2, no. 1, pp. 111-124, 2016.

[6] S. R. U. A. S. Sokop, Jendri Steven, Dringhuzen J. Mamahit, "Trainer Periferal Antarmuka Berbasis Mikrokontroler Arduino Uno," E-Journal Tek. Elektro dan Komput., vol. 5, no. 3, p. 14, 2016.

[7] Y. E. Rohmadi, T. Ginting, and D. Warasto, "POSITIONING DENGAN TEKNOLOGI BLUETOOTH," vol. XV, no. 1, pp. 58-65, 2016.

[8] M. H. Muhamad Saleh, "Jurnal Teknologi Elektro , Universitas Mercu Buana RANCANG BANGUN SISTEM KEAMANAN RUMAH MENGGUNAKAN RELAY Muhamad 
Saleh Program Studi Teknik Elektro Universitas Suryadarma , Jakarta Program Studi Teknik Elektro ISSN : $2086 \square$ 9479,'

Tek. Elektro, vol. 8, no. 3, pp. 181-186, 2017.

[9] A. Dinata, Fun Coding with MicroPyton. Jakarta: PT Elex Media Komputindo, 2018.

[10] C. Cholish, R. Rimbawati, and A. A. Hutasuhut, "Analisa Perbandingan Switch Mode Power Supply (SMPS) dan Transformator Linear Pada Audio Amplifier," CIRCUIT J. Ilm. Pendidik. Tek. Elektro, vol. 1, no. 2, pp. 90-102, 2019. 